\title{
UN EJEMPLO TARDÍO DE RIEGO DE BOQUERA: LA PRESA DEL MADROÑAL (IBI)
}

\author{
Margarita Box Amorós
}

\begin{abstract}
RESUMEN
La utilización de las aguas de lluvia para el riego de cultivos de secano, mediante la construcción de presas y canales de derivación, es una práctica que remonta sus orígenes a época romana, pero cuya pervivencia alcanza el siglo actual. El tema central del trabajo es, precisamente, el desarrollo de un proyecto de construcción de este peculiar riego de boquera en los albores del s. XX, y en la comarca de la Hoya de Castalla (Alicante).

\section{RÉSUMÉ}

L'utilisation des eaux de pluie pour l'arrosage des terrains non irrigués («secano»), grâce à la construction des barrages et des canaux de dérivation, c'est une practique qui remonte à l'époque romaine, et qui survie jusqu'à nos jours. Le sujet principal de cet article c'est justement le développement d'un projet de construction du systhème d'arrosage de «boquera» au début du XXème siècle, et dans la contrée de la Hoya de Castalla (Alicante).
\end{abstract}

Abancalamiento de laderas montañosas y riegos de boquera representaron en las tierras del SE. peninsular los sistemas más extendidos para la conservación del suelo y el agua, elementos escasos e imprescindibles para el desarrollo de una agricultura de secano desprovista de las posibilidades de suministro hídrico procedente de cursos continuos.

Aún y cuando cabe retrotraer el empleo de estas técnicas a época romana, sin lugar a dudas, es a partir del s. XVIII cuando adquieren extraordinario desarrollo. En la actualidad, el empleo de nuevas técnicas agrícolas y de regadío, así como la posibilidad de poder disponer de caudales foráneos, han sido las causas del continuo retroceso de terrazas agrícolas y del abandono de buena parte de los riegos de boquera, con lo que 
ello implica de incremento de coeficientes de escorrentía y de volúmenes circulantes por barrancos y ramblas cuando se producen copiosas precipitaciones.

No obstante, el campo destinado a cultivos de secano, situado en topografías donde el riego regular enfrentaba dificultades de orden técnico y económico, siguió conservando sus ancestrales sistemas de cultivo y riego hasta fechas recientes; lo llamativo de esta situación es que no sólo se aprovechan las infraestructuras preexistentes sino que, incluso, en el s. XX se procede a la construcción de presas para aprovechar las aguas de avenida.

Efectivamente, conservado en el Archivo del Ministerio de Obras Públicas y Urbanismo (delegación de Alicante), se encuentra el Proyecto de presa de toma y canal de derivación para riegos en la heredad Pla de San Pere (término de Ibi, provincia de Alicante), que corresponde al estudio y propuesta de construcción, en 1918, de una presa de derivación y boquera lateral, cuya importancia radica en lo tardío de su ejecución, poniendo, por ello, de manifiesto la enorme trascendencia que para el agricultor de estos sedientos campos, poseía cualquier posible aporte hídrico y su interés en aprovechar al

máximo la escasa agua de lluvia, no dejándola perder en el mar.

La heredad que se pretende beneficiar con el proyecto se sitúa en la comarca alicantina de la Hoya de Castalla, recorrida de norte a sur por el río Montnegre. Constituye este espacio, como su nombre indica, una cuenca deprimida y flanqueada en todo su contorno por elevadas sierras calizas en las que tienen su cabecera multitud de barrancos que avenan al río Montnegre y que se encajan tanto en estos materiales, aprovechando líneas de debilidad tectónica, como en los glacis, conos de deyección y terrazas fluviales que tapizan los piedemontes y el fondo de la cubeta. Se trata de un ámbito donde el aprovechamiento agrícola posee hondas raíces históricas, con un dominio casi exclusivo de cultivos de secano instalados en los aluviones cuaternarios que el hombre ha abancalado en terrazas para su adecuada utilización agrícola.

Limitando la Hoya de Castalla por el este, se desarrolla un conjunto montañoso integrado, entre otras, por la sierra del Cuartel $(1.035 \mathrm{~m}$.), cuya vertiente occidental drena sus aguas hacia el barranco de Ibi, tributario del río Montnegre, a través de numerosos barrancos, entre ellos, el conocido como barranco del Madroñal, en el que se pretende instalar la presa. Se trata de un curso seco la mayor parte del año, circunstancia ésta que permite el establecimiento de cultivos en su lecho, mediante el correspondiente aterrazamiento y por el que únicamente circula agua cuando se producen abundantes precipitaciones.

El objetivo del proyecto que se analiza es el de aprovechar estas aguas para el beneficio de una heredad situada en su margen derecha, la heredad «Pla de San Pere», ubicada en término de Ibi, partida «dels Plans», propiedad, en esos momentos, de Vicente Botella Miralles, arquitecto y autor, a su vez, del proyecto, que integraba, según consta en la certificación del Registrador de la Propiedad del partido de Jijona incluida en el expediente formado para la tramitación del proyecto, las siguientes pertenencias ${ }^{1}$ : casa-corral de $340 \mathrm{~m}^{2}, 21$ jornales (11 ha., 52 áreas y 96 centiáreas) de tierra secana, plantada de olivos, almendros y parras; 3 horas de arar de tierra huerta con olivos que se riegan de la fuentecilla de la heredad y balsa enclavada en sus tierras; 60 jornales (29 ha., 91 áreas y 93 centiáreas) de monte denominado «Pinar de Sempere», del que se ha

\footnotetext{
${ }^{1}$ Archivo del Ministerio de Obras Públicas y Urbanismo (delegación de Alicante) (en adelante A.M.O.P.U.A.), Expediente instruido para la tramitación del Proyecto de presa de toma y canal de derivación para riegos, en la heredad Pla de San Pere, término de Ibi, provincia de Alicante. Madrid, 1 de octubre de 1918, Certificación del Registrador de la Propiedad del Partido de Jijona.
} 


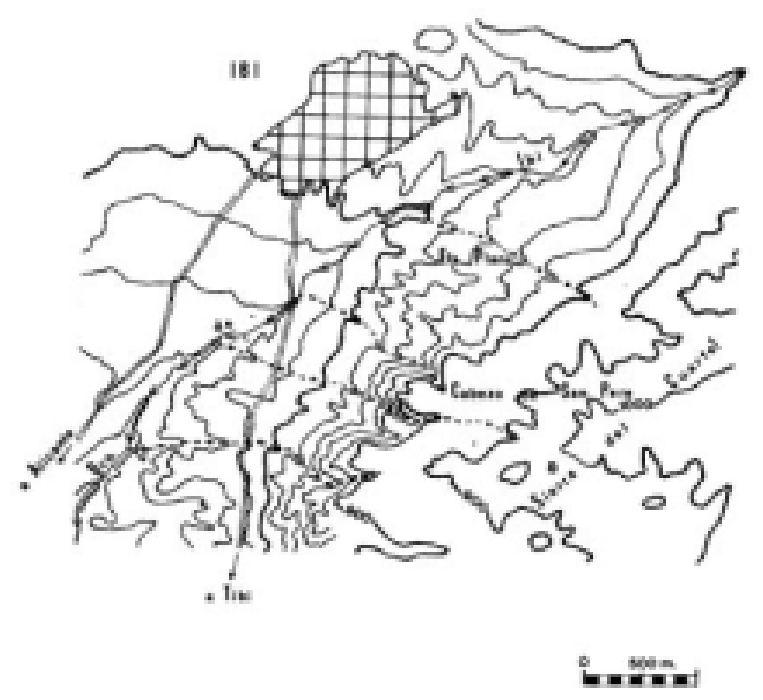

Mapa general de situación del área de estudio. A. localización de la presa del Madroñal.

convertido parte en tierra culta; y una suerte de tierra secana plantada de olivos y parras que comprende 9 áreas y 60 centiáreas, en la partida del Pla de Miguel Ángel.

La propiedad incluía tanto terrenos de piedemonte como una parte del mencionado barranco del Madroñal y recibía únicamente el beneficio de las aguas de lluvia. Dos eran los sistemas utilizados para el aprovechamiento de las esporádicas precipitaciones. De un lado, el tramo de la finca perteneciente al barranco, de alrededor de media hectárea, se encontraba dividido en cuatro parcelas escalonadas, separadas por malecones o diques de piedra en seco en los que se había practicado una abertura o sangrador, de forma que las aguas aportadas por fuertes precipitaciones «... van cubriendo la primera parcela hasta que subiendo de nivel y ganando el portillo del primer malecón llegan a la segunda parcela, de ésta pasan a la tercera por la apertura del malecón correspondiente, de ésta pasan a la cuarta en igual forma dejándolas todas inundadas, y finalmente en el cuarto malecón que constituye la linde y que está formado por un dique de piedra y un espeso cañar quedan retenidas todas las aguas que vienen discurriendo por el barranco, a 


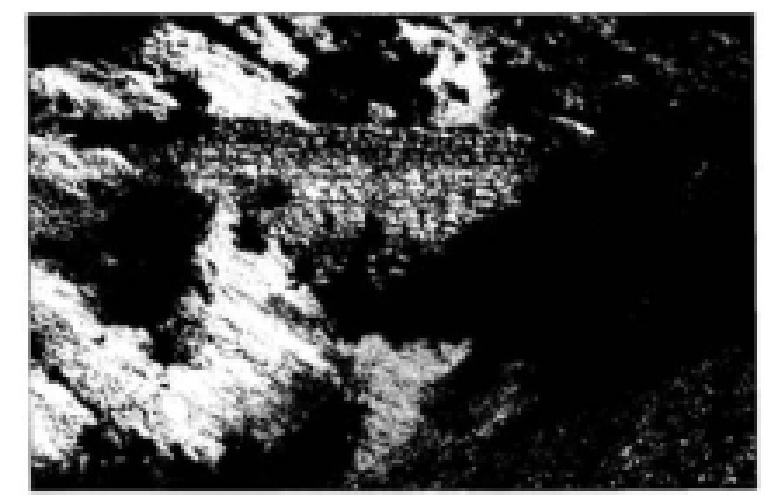

Foto 1. Vista frontal de la presa del Madroñal.

excepción de rarísimas y grandes avenidas, en que saltando o rompiendo dicha linde inundan las parcelas inferiores de las fincas inmediatas» ${ }^{2}$.

Los terrazgos situados en el piedemonte de la elevación denominada Pinar de Sempere o San Pere, aparecen también dispuestos en parcelas escalonadas y las únicas aportaciones hídricas que recibían eran las procedentes directamente de las lluvias y las dirigidas por un canal, que en el proyecto se denomina agüera, cuya finalidad era la de recoger la escorrentía difusa procedente del citado monte. Efectivamente, el término agüera (lat. aquarium) puede ser definido como una «zanja para encaminar el agua llovediza a las heredades», y en su Informe sobre los Monnegros, Ríos Romero las describe como «anchas regueras que recogen el agua de las tormentas de todos los campos limítrofes para conducirlas al campo que se cultiva» ${ }^{3}$. La diferencia básica entre el término boquera y el de agüera reside en que en el primero la interceptación de la escorrentía se efectúa mediante una presa instalada en el lecho del barranco, mientras que en el segundo, el obstáculo es inexistente.

Con el objetivo de aprovechar al máximo las aguas circulantes por el barranco del Madroñal, con ocasión de fuertes aguaceros, y beneficiar así una parte de la finca, el proyecto que se analiza contempla la instalación en el lecho de la rambla de un pequeño dique, presa o azud de $3,20 \mathrm{~m}$. de altura, del que, por su margen derecha parte un canal de derivación de aguas o boquera. Lógicamente, este último se encuentra en una posición superior a la del fondo del barranco, por lo que la posibilidad de distraer

\footnotetext{
${ }^{2}$ A.M.O.P.U.A. «Proyecto de presa de toma y canal de derivación para riegos en la heredad Pla de San Pere, término de Ibi, provincia de Alicante». Documento 1, Memoria descriptiva, pp. 1-2.

${ }^{3}$ RÍOS ROMERO, F.: «Informe sobre los Monnegros», Geographicalia, 1980, Univ. de Zaragoza, p. 25.
} 
caudales en los momentos de fuertes precipitaciones, sólo sería factible cuando el nivel de las aguas hubiera alcanzando su misma cota. Precisamente por ello, en el proyecto se especifica que la presa que se pretende construir no tiene como finalidad la de producir embalse permanente «... sino para elevar el nivel de las aguas y con el tiempo cuando se llene de piedra el embalse, subirá el cauce del barranco que tiene una pendiente media de un $10 \%$, y las aguas en sus avenidas tomarán el nivel conveniente» ${ }^{4}$.

La presa se construiría de mampostería ordinaria «con la piedra arrancada de la ladera derecha del barranco para abrir y construir el canalillo de toma ${ }^{5}$ y con mortero de cal en su interior. El paramento ofrece una sección frontal de forma trapezoidal, lógicamente adaptada a la morfología del talweg del barranco, con $2 \mathrm{~m}$. de anchura en su base y $10 \mathrm{~m}$. en la coronación del muro, y altura de la presa de 3,20 m. En sección lateral la presa ofrece, igualmente, forma trapezoidal, de manera que «... las hiladas no serán horizontales sino sensiblemente normales al talud o paramento exterior para que los lechos sean aproximadamente normales a la dirección de los esfuerzos» ${ }^{6}$, por ello el grosor del muro experimentaría un progresivo decrecimiento pasando de 2,45 m. de ancho en la base a 0,50 m. en la coronación.

Edificada la presa, la operación siguiente sería la excavación del canal de derivación de aguas que, como se ha señalado, realizaría la toma por el vértice derecho del azud. La boquera tendría una anchura de $0,60 \mathrm{~m}$. y sería realizada de mampostería ordinaria con mortero de cal y sus paredes y solera enlucidos con mortero hidráulico. Este tipo de construcción tendría un desarrollo de alrededor de $20 \mathrm{~m}$. ya que el resto de la boquera sería de tierra hasta enlazar con la agüera preexistente.

A diferencia de construcciones similares realizadas en siglos anteriores, el proyecto que ahora se analiza especifica el caudal máximo que podría ser derivado por la boquera. Recordemos que en los momentos en que se redacta el proyecto, se encuentra en plena vigencia la Ley de Aguas de 1879 que regula el aprovechamiento de aguas superficiales y subterráneas. En su articulado, la ley prescribe que este tipo de utilizaciones únicamente podría distraer un caudal máximo de 100 l/s. ${ }^{7}$, que es el que se solicita en el proyecto, adecuando las secciones de la embocadura del canal a esta imposición legal.

$\mathrm{Si}$ las precipitaciones fueran excesivamente copiosas y el agua circulante superara el módulo de 100 1/s., el exceso de dicho aforo «saltará por la cresta o vertedero de la presa al barranco» ${ }^{8}$, y para que estas aguas sobrantes llegasen «mas facilmente que ahora a los predios inferiores, se construirá una reguera o agüera de tierra y piedra suelta por el fondo y se abrirá un portillo en el cuarto malecón o sea en la linde del Pla con lo cual se evitará el perjuicio que se pudiera irrogar a dichas parcelas inferiores que han gozado siempre del exceso de agua en mayores avenidas». No obstante, con el objeto de salvaguardar los derechos de los terrazgos aguas abajo y asegurar la llegada de caudales a los mismos, la División Hidráulica del Júcar, en informe emitido en 26 de agosto de 1919, considera que la obra proyectada «deberá completarse mediante el establecimiento de un vertedero lateral en el origen del canal, formado por una escotadura practicada en el cajero recayente al cauce del barranco, cuyo umbral quede enrasado a la igual

\footnotetext{
${ }^{4}$ A.M.O.P.U.A. Proyecto de presa de toma y canal de derivación... Doc 1. Op. cit., p. 2.

${ }^{5}$ A.M.O.P.U.A. Proyecto de presa de toma y canal de derivación... Doc 1. Op. cit., p. 3.

${ }^{6}$ A.M.O.P.U.A. Proyecto de presa de toma y canal de derivación... Doc 1. Op. cit., p. 8.

${ }^{7}$ Ley de Aguas de 1879 (art. 179).

${ }^{8}$ A.M.O.P.U.A. Proyecto de presa de toma y canal de derivación... Doc. n. ${ }^{\circ}$ 1, pág. 3.
} 


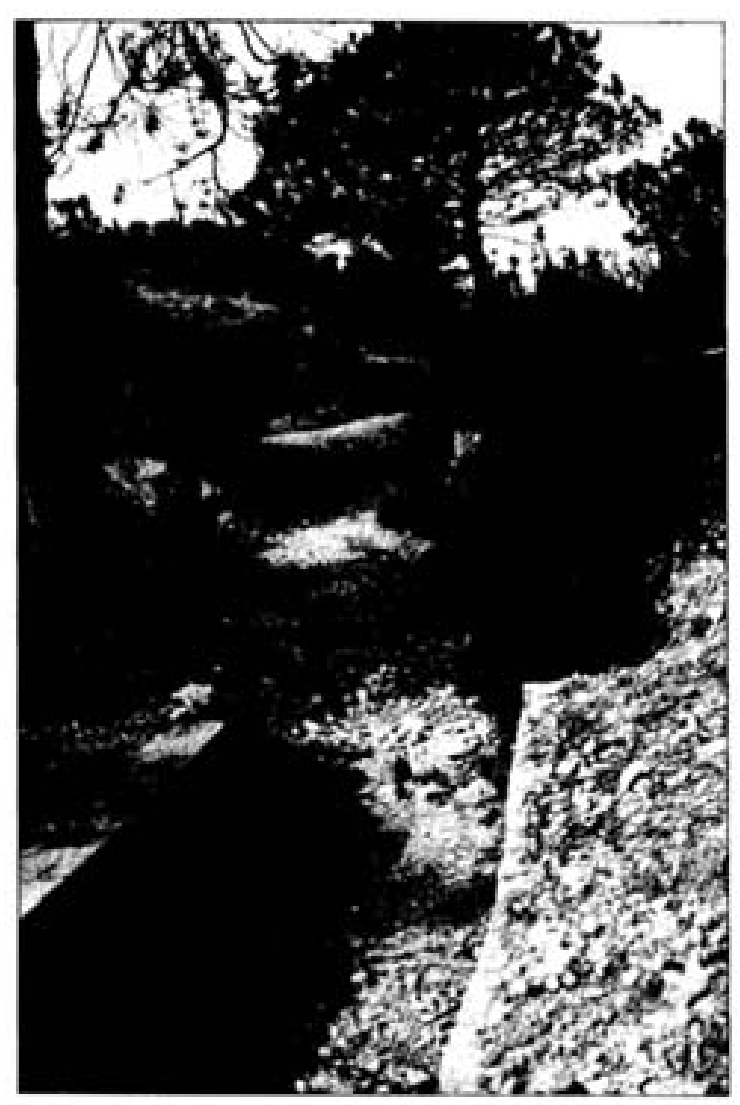

Foto 2. Tramo final de la boquera y enlace con la agüera preexistente.

altura que la coronación de la presa y tenga la misma pendiente que el fondo del canal» ${ }^{9}$.

Con fecha 13 de abril de 1920 y tras los informes emitidos por la División Hidráulica del Júcar, se aprobó la concesión para el levantamiento de la presa, si bien su construcción sufrió un cierto retraso por la reclamación efectuada por D. Francisco Bernabeu Botella, propietario de los terrenos de la margen izquierda del barranco del Madroñal donde debía tener su apoyatura uno de los estribos de la presa. Basa su protesta en que el solicitante «trata solamente de aprovecharse de unas aguas sobre las que el recurrente, con otros propietarios tiene derechos legalmente adquiridos y perjudica al propio tiempo en gran manera la propiedad del que dice» ${ }^{10}$.

${ }^{9}$ A.M.O.P.U.A. Expediente instruido para la tramitación del Proyecto de presa de toma y canal de derivación... Op. cit. Informe de la División Hidráulica del Júcar (Valencia, 20 de agosto de 1919).

10 A.M.O.P.U.A. Expediente instruido para la tramitación del Proyecto de presa de toma y canal de derivación... Op. cit., Escrito de D. Francisco Bernabeu Verdú de 30 de junio de 1920. 
Se planteó, pues, un problema de servidumbre forzosa de estribo de presa que, con base en el informe de la División Hidráulica del Júcar emitido en 20 de agosto de 1919 y en el que se argumentaba que «... la fuerte pendiente del barranco del Madroñal, hace que la longitud del remanso producido por la presa sea poco más de $50 \mathrm{~m}$., contados según las sinuosidades del cauce y como en todo el recorrido discurre el barranco totalmente encajonado entre montes de bastante altura no hay peligro de inundar fincas de otros particulares», quedó concluido, finalmente, el expediente con la Resolución del Gobierno Civil de la provincia de 16 de febrero de 1921 en la que se decreta la imposición de la misma ${ }^{11}$, previo pago al dueño del predio sirviente el valor del terreno que se ocupase con el estribo y el remanso, según prescribía el art. 104 de la ley de aguas vigente.

Concluida la tramitación y salvados los distintos inconvenientes técnicos y legales, dio comienzo, en 1921, la construcción de la presa que, aún hoy conserva prácticamente intactos sus elementos fundamentales, si bien su utilización para el aprovechamiento de turbias es, en la actualidad, inexistente, al quedar la presa completamente terraplenada y por el abandono agrícola de los terrazgos. Todavía es posible contemplar la casa de la finca, una sólida masía típica de estas tierras que, semiarruinada, aún conserva las instalaciones de una notable almazara.

Dada su tardía construcción, la presa del Madroñal representa un ejemplo donde es posible conjugar aprovechamiento tradicional de aguas de avenida y aplicación de normas legales para la construcción de estos ancestrales sistemas de riegos de boquera, al tiempo que permite establecer premisas que, no por sabidas y conocidas, resultan menos trascendentales para la ordenación del territorio, máxime cuando el elemento que se analiza es, precisamente, la impronta de las avenidas en los tramos bajos de los ríos.

Efectivamente, instalados en múltiples barrancos y ramblas, la distracción de caudales por estos sistemas de desviación de turbias para el riego supuso volúmenes considerables y, buena prueba de ello es el siguiente párrafo, contenido en la Memoria Descriptiva del proyecto que se trata «... por que público y notorio es para todos los habitantes de la comarca, que pueden dar fé de que en rarisimas ocasiones las aguas saltan el dique o linde de la finca del Pla, llegando a las tierras inferiores solamente en las mayores avenidas...».

Arruinados hoy buena parte de los aterrazamientos y la casi totalidad de presas y boqueras, las escorrentías ni se desvían ni retienen y basta un pequeño aguacero para que barrancos y ramblas acojan, con prontitud, en sus lechos, aguas que se incrementan progresivamente en volumen hacia la desembocadura, produciendo funestas consecuencias en unos espacios cuya planificación queda desconectada de las modificaciones experimentas por los tramos altos de las cuencas fluviales.

${ }^{11}$ B.O.P.A. de 19 de febrero de 1921. 